$\mathrm{PhD}$ in Jurisprudence, Associate Professor, DMYTRO KYSLENKO

The Institute of the State Security Management of

Taras Shevchenko National University of Kyiv Address: 8 Petro Bolbochan St., Kyiv, 02000, Ukraine

E-mail: kyslenko.d@gmail.com

\title{
USING INFORMATION TECHNOLOGIES IN PROFESSIONAL TRAINING OF FUTURE SECURITY SPECIALISTS IN THE USA, GREAT BRITAIN, POLAND AND ISRAEL
}

\begin{abstract}
The paper discusses the use of information technologies in professional training of future security specialists in the United States, Great Britain, Poland and Israel. The probable use of computer-based techniques being available within the integrated Web-sites have been systematized. It has been suggested that the presented scheme may be of great significance for organization of security specialists' professional training in Ukrainian higher education institutions as it promotes searching for an individual paradigm in processing various data and adjusting to modern challenges of an information soceity. The process of expanding learning techniques through information technologies has been emphasized; four directions of US Education Reform have been outlined; the distinctive features of theory and methodology of using information technologies in the United States have been highlighted. The learning models in Israel have been described; the aim of future specialists' training in Poland has been formulated. The methodological and practical components offuture security specialists' training of have been analyzed. It has been indicated that nowadays Great Britain has the most detailed education standards in Europe. It has been pointed out that studying experience of other countries contributes to determining a strategy for using information technologies in education. It has been concluded that methodical and practical training of future security specialists for using information technologies should be related to practical skills. It has been found out that motivation play an important role in developing future security specialists' practical skills. It has been proved that pedagogical professionalism promotes achievements of science and technology. Prospects for further researches are seen in studying the peculiarities of professional training of future security specialists in leading European countries.

Keywords: information technologies, education, security activity, future specialist's training, university.

\section{INTRODUCTION}

The development of society requires improving all spheres of life, including security activities. A security specialist has always been in demand at different times. Today, as practice shows, inadequacy in training and development of purposeful qualitative features in professional training of security specialists, as well as the lack of approaches to forming a range of relevant professional abilities and skills are the main effects of the problem of security specialists' training.In addition, the global transition to an information society, as well as economic, political and social changes that are taking place nowadays
\end{abstract}


acceleratereforming education systems. A future security specialist must possessbasic Internet skills, be able to understand how the services of the global network are organized, what resources can be used to replenish their methodological knowledge, how to enhance their professional experience. Also future security specialistsmustpossess knowledge, skills and ability to organize and execute the search for the required information stored in web documents, by communicating with their colleagues via email.

In Ukraine, the process of training computerization began relatively long ago and develops at an accelerated pace. This is due to the emergence of computers and integrated information systems of the new generation and the massive introduction of them into educational institutions of different types and levels of accreditation. It should be emphasized that the massive appearance of information technologies has contributed to raising the interest in professional training of future security specialists within the national dimension.

THE AIM OF THE STUDY

The paper is aimedat studying is to analyze using information technologies in professional training of future security specialists in the United States, Great Britain, Poland and Israel.

\section{THEORETICAL FRAMEWORK AND RESEARCH METHODS}

The problems of future security specialists' professional training in the context of using information technologies have been fully and partially covered in many works of foreign scholars, namely, by B. Collis (2013) (information technologies for education and training), N. Davis (2003) (technology in teacher educaton in the USA), D. Denning (1998) (information security and welfare), L. Harasim (2006) (onlinecollaborativelearning (a theory, methodology and toolset)), S. Hooper \& L. Rieber (1995) (teaching with technology), A. Lane (2012) (open educational resources' participation in higher education), H. MeisharTal, Y. Yair \& E. Tal-Elhasid (2010) (Wikis at the Open University of Israel), M. Sherman (2009) (information technologies in educational dimensions), L. Tomei (2007) (distance learning) et al. In addition, we have used relevant materials prepared by U.S. Education Department (transforming American education and learning powered by technology) and UK Government (Government information technology), as well as other sources, namely, EC-Council CISO (CCISO training of security specilalists), ISA-Israel (academic/theoretical distance cerfitication of security specialists) etc.

Our research framework is based on the application of such methods as comparative analysis with the use of individualization and generalization.

\section{RESULTS}

Since 1971, European countries and the United States have started equipping their educational institutions of all levels with computers. The complex and rapidly changing needs of the world economy prove the need for updating the content of professional training of various specialists, in particular security specialists, as well as promoting teaching staff advanced training. Therefore, nowadays it is extremely important to use available computer technologies in training motivation of future security specialists toward professional activity.

Unlike traditional teaching in a classroom, where more than one teacher often transmits the same educational material to all students in the same way, computer-based learning places the student in the center and provides them with the opportunity to take control of their individual learning, ensuring flexibility in several dimensions. The basic set of standard knowledge and skills form the foundation which all students should master, but also the students and the teachers may choose whether they want to study in large or small groups, as well as ajust their learning to their individual goals, needs and interests (Hooper, \& Rieber, 1995). 
B. Colis (2013) believes that the major breaktrough in information technologies in the system of education followed the introduction of the WWW andthe Internet since they became ratherachieavable to usersin the 1990s. Despite the fact thatthe WWW, the Internetand information technologies had been mainly used in teaching and learning (both by learners and professional educators or occassionally for different researches and projects) since the 1970s, it was the Internet and particularly the WWW that launched a new phase of computer use due to their public breakthrough in the early 1990s that began. It should be mentioned that users still used their computers, but more frequently for maintaining contact with other computers, individuals as well as networked resources via data communications. This has powerfully influenced information technology in education. Thus, there has origianted a creative individual who is able to produce their own computer-based recourses (Colis, 2013, p. 5).

Security specialists are often management-level security professionals who might work for government agencies, like the armed forces branches, the Department of Homeland Security, or private industries interested in protecting intellectual or physical property. This work is often routine and predictable but may turn dangerous. According to D. Denning (1998), lately, information wars have influenced the activities of government officials and, surely, information security specialists. Thus, future security specialists should be accquianted with information technologies to cope with a wide range of problems, including computer sabotage and break-ins, intelligence operations and espionage, electronic warfare, perception management, fraud, telecommunications eavesdropping etc.

M. Sherman (2009) indicates that traditional models of education have quickly and easily adapted to the new technologies. The 2005 edition of Peterson's Guide to Distance Learning lists more than 4,800 online learning programmes at more than 1,000 accredited schools in the United States and Canada. The number is growing, if not exponentially, then surely steadily as colleges and universities everywhere scramble to diversify their programmatic offerings and attract new constituencies of students by adding distance learning opportunities to their more traditional face-to-face classroom schedules. The fairly straightforward and technologically sophisticated procedures of recording faculty presentations, posting syllabi and assignments, sharing documents, administering examinations and devising ways to receive, grade abd assess student learning have enabled colleges and universities to emulate many features of the traditional lecture hall model of education. The scholar states that more complicated are the methods for facilitating interaction between students and instructors or among students; but here, too, information technology has provided opportunities and formats for interaction through threaded discussions, asynchronuous online forums and real-time "chat-rooms" that survive to emulate the intimacy of the seminar room. For progressive educators, especially the new technologies raise new questions about how students will learn individually and together, and how teachers will participate in student learning (Sherman, 2009).

Of great significance for our study are the probable use of computer-based techniques being available within the integrated Web-sites in the context of using information technologies (see Table 1) (Colis, 2013).

As one can see from Table 1, in terms of a process, information technology can be described as computers' processing the information via software. It can be associated with both processes and products; hardware, software, information systems, data communication, database management etc. (Colis, 2013). In our opinion, the presented scheme may be of great significance for organization of security specialists' professional training in Ukrainian 
higher education institutions as it promotes searching for an individual paradigm in processing various data and adjusting to modern challenges of an information soceity.

Table 1

The probable use of computer-based techniques being available within the integrated Web-sites

\begin{tabular}{|l|l|}
\hline \multicolumn{1}{|c|}{ Major purpose } & \multicolumn{1}{|c|}{ Applications that can be integrated with Web sites } \\
\hline $\begin{array}{l}\text { Publication, infomation, } \\
\text { dissemination }\end{array}$ & $\begin{array}{l}\text { HTML editors; web sites and browers to access them; web sites } \\
\text { associated with database environements; software to facilitate file } \\
\text { transfer and document attachment to email; tools for cross-application } \\
\text { format retention (e.g. pdf) }\end{array}$ \\
\hline Communication & $\begin{array}{l}\text { Email systems, computer conferencing tools, including WEB-boards and } \\
\text { other formats of Web-based conferencing; Web sites offering } \\
\text { communication options including mailto: for the direct sending of Email } \\
\text { and CGI (common gateway interface) forms for structured } \\
\text { communication; software for Internet telephony; software environments } \\
\text { for audio/video desktop conferencing, for voice-Email, for creating } \\
\text { video attachments for Email; software systems for text-based chat }\end{array}$ \\
\hline Collaboration & $\begin{array}{l}\text { Groupware, which includes application-sharing software, shared } \\
\text { workspaces, Web-based shared workspaces, Web-based application } \\
\text { sharing, workflow tools; computer conferencing suites; Web-sites } \\
\text { designed for collaboration support; tools to allow collaborative writing } \\
\text { ondocuments that are then commonly available to a group }\end{array}$ \\
\hline $\begin{array}{l}\text { Information } \\
\text { and resource handling }\end{array}$ & $\begin{array}{l}\text { Web-based search engines: distributed database systems (Web- and } \\
\text { proprietary); Web sites designed for information organization, access } \\
\text { and sometimes creation; tools to retrieve and display distributed } \\
\text { multimedia resources stored as digitized audio and video (including } \\
\text { streaming audio and video) }\end{array}$ \\
\hline $\begin{array}{l}\text { Specific for teaching } \\
\text { and learning purposes }\end{array}$ & $\begin{array}{l}\text { Applets for interactive sofrware (such as tutorials, quizzes, simulations) } \\
\text { accessible via Web sites; testing systems accessible accessible via Web } \\
\text { sites; video-capture tools for lecture or presentation capture; video } \\
\text { conferencing (point-to-point and multicasing) for lecture participation; } \\
\text { video-on-demand and streaming video for lecture capture and reuse; } \\
\text { Web-based course support environments; database-generated course } \\
\text { support systems, integrating many or all of the applications in this table } \\
\text { along with management tools }\end{array}$ \\
\hline
\end{tabular}

In the education system of the United States, Internet technologies are used to measure the knowledge of future security specialists, which enables using the obtained evaluation data to continuously improve the education process.

The following steps are needed to improve the education process:1) in the statesand districts, it is necessary to design, develop and implement evaluations that provide future security professionals, teachers and other stakeholders with timely and up-to-date data on educational achievements of future security specialists to enhance theiracademic level and the level of practical skills; 2) scientific potential of teachers and Internet technology developersshould be used to improve assessment in the education process. Using Internet technologies, one can measure effectiveness of learning, providing the education system with the ability to design, develop and test new and more effective assessment methods; 3) it is important to conduct researchesto find out how using a technology, such as simulation, learning environments, virtual worlds, interactive games 
and curricula can encourage and motivate students when assessing complex skills; 4) it is important to develop an objective assessment (without assessing additional skills of the students). In order for the assessment to be objective, oneshould measure the required qualities thatcannot depend on external factors; 5) it is crucial to review practices, strategies and rules for ensuring confidentiality and protecting data on student assessments, while ensuring a model of assessment, which includes a constant collection and exchange of data for continuing improving the assessment process (Tomei, 2007).

All students should have the right to access their assessment data in the form of electronic records, thus knowing their level of knowledge. Simultaneously, student data should be open to other students as well.

As the learning environment is constantly becoming more and more complex, within connected classroom learning the teachers are supported in organizing and managing the education process. Open source learning management systems are already widely used at US universities. Such tools allow the teachers to determine the content of teaching materials, curricula, tasks, discussions, are more focused on the students' needs. The use of online environments allows creating virtual classes in which the teachers and the students can interact with each other, managing the content of the course. Such educational environments provide the opportunity to leave samples of homework, exam papers, hold discussions and place animated objects, provide feedback to the students, and presentthe classified material them (Educational Technology, 2017).

To the students to achieve the learning goals, the teachers should undergo advanced training for using online technologies that can enable them to access their teaching materials, content, resources, learning experience and enhance the effectiveness of the education process. The following actions are required to make it possible: 1) it is necessary to provide the teachers with access to information technologies used to preserve, modify and process educational materials at any time convenient for them; 2 ) it is important to use social networks and platforms for creating a teacher community that enhances their personal and professional development, provides them with access to learning resources and resources that make professional training timely and relevant, as well as progressive activities of those teachers, who are constantly improving and developing; 3 ) it is crucial to use Internet technologies to support online student learning, increasing learning efficiency and providing great opportunities for mixed learning;4) it is recommended to ensure quality of teachers' training for using information technologies in their teaching and enhance teachers' digital literacy and encourage them to develop interesting tasks for the students to be able to improve their educational achievements etc; 5) it is imperative to train qualified specialists who are able to effectively use information technologies (Davis, 2003).

In 2009, US Education Secretary Arne Duncan in his speech urged education leaders to focus on four areas of education reform, namely, raising the level of secondary education; adopting rigorous standards that train future security specilaists to succeed in university studies and workplace; creating information systems for tracking educational achievements of future security specialists as well as teachers' achievements; involving in the organization of the education process highly skilled teachers, especially for those classes where modern information technologies are used (U.S. Department of Education, 2009).

To address these challenges, U.S. Department of Education has issued the document entitled "Transforming American Education. Learning Powered by Technology. National Education Technology Plan 2010". The document requires using advanced technologies in everyday work throughout the education system to improve student 
learning, accelerate implementation of good practices and enhance their continuing improvement (U.S. Department of Education, 2010). It contains five recommendations that can be used by the states, districts, federal governments etc. The abovementioned recommendations address five core components of computer-based learning: teaching and learning, assessment, methodology and productivity (U.S. Department of Education, 2010).

Relevant for our study is the experience obtained by Security Specialists Organization founded in 1999 in Southern California. Their database technology is built and designed based on the latest information technologies. For instance, they provide any and all of theircomputerized reports through email with photos on a daily, weekly or monthly basis.The purpose their database serves is for quick and accurate access of data company-wide and rapid delivery of reports. Security specialists access their database directly from laptop computers located in each patrol vehicle. This enables security specialists to generate their daily reports on the computer, communicate with their central station and other patrol units, and to instantly monitor and access data such as Client Records and Instructions, Current Updates and Bulletins, Service Calls, Area Maps and Navigation, Location Rules and Regulations, Resident Registries, Vehicle Registries, Database of Suspects (with digital photos), Database of Vehicle Citations and Impounds (with digital photos), Database of Previous and Current Incidents and Events. Their database technology is today's flagship in the security industry and comes standard with all of the Patrol and Response Services (Security Specialists, 2017).

Thus, one can distinguish the following specific features of theory and methodology of using information technologies in the United States: 1) wide introduction of computer networks, bringing together the teachers and the students; 2) development of theory and methodology of using web-technologies in education; 3) development of training management systems. In addition, in today's highly competitive and global economy of the United States, education is not limited to classroom-based learning. The use of information technologies in professional training of security specialists contributes to traditional education and assists the students' inlifelong learning. Computer-based learning provides motivation toward learning both inside and outside the classroom. These new learning systems provide an individualized approach to students' needs in terms of the content (what they learn) and methodology (how they are taught).

We also believe it necessary to characterize the use of information technologies in professional training of security specialists on the example of Israeli experience. Thus, the Open University of Israel (OUI) founded in 1975 is one of the eight Israeli universities. This is a higher education institution that combines distance learning with a very high level of flexibility of the education process, which includes more than 40 thousand students who intend to master bachelor or master programmes. The Open University in Israel developed an online platform (named OPUS) of its own in 1996. The high academic level of teaching materials offered to the students and teaching quality have created the Open University's reputation as one of the best educational institutions in Israel (The Open University of Israel, 2017).

Each course in the OUI has a website to which the course staff can upload learning materials, such as briefs, presentations and enrichment material. Each course has its own message boards and discussion groups, to which messages are relayed by the course team, and where the students can post questions and queries, which the course staff or their peers can answer and discuss. The adoption of e-learning technologies is dictated by the pedagogical goals of the university and the students' needs. As a distance learning university, OUI students can benefit from using an online learning environment, which allows them better 
contact with the academic staff, better access to learning materials and an opportunity to collaborate from a distance (Harasim, 2006; Meishar-Tal, Yair, \& Tal-Elhasid, 2010).

Applying the latest advances in science and technology allows the University to improve the level of services provided to the students, both in terms of teaching materials and in terms of teaching methodology. These facilities, as needed, are included in the curriculum as a supplement to the printed textbooks that are being prepared for each course in all fields of knowledge.

Of great significance for our study is also the organization entitled "ISA - Israel" that has specialized in training security specialists since 1987. They have successfully developed a very sophisticated and most up to date Israeli instruction platform with a unique and comprehensive Security Instruction Manual that they call the "Security Bible". Thus, the students should complete the following stages to obtain access to their educational material. First of all, they should register to the Academic/Theoretical Distance Online Programme (purchase the chosen programme and its modules as well as send an up-to-date passport picture). After that, they receive comprehensive instruction material that contains presentations and links to enhance and upgrade their knowledge as described in the syllabus of each of the programmes. Successful completion of the independent distance study training requires discipline. They recommend that the students study at their own pace to guarantee a complete, relaxed and thorough study experience. Once they have completed all the programme's Module's contents, they should be ready to take Academic/Theoretical Distance Online Programme examination for the course they purchased (ISA-Israel, 2017).

So, in Israel it is assumed that the education system should provide free access to all possible learning technologies, which will ensure effectiveness of the education process, assessment, teaching etc in the context of professional training of security specialists. In addition, the use of information technologies greatly simplifies the process of education management, increasing its productivity.

The aim of future security specialists' training in Poland is to combine their basic knowledge and skills necessary for implementing professional tasks. In addition, such training is intended to intensify the interests and motivation for permanent improving their experience and constant self-control. To realize the mentioned tasks, it is crucial to fulfill multidimensional tasks contained in three dimensions: the content (the tasks related to refining the goals of learning, as well as selecting and improving the content of subjects); organization (teaching professional and interdisciplinary subjects; application of innovative methods and practices); realization (significant contact between the teachers implementing methodology; joint care about the high level and preservation of connections between theoretical knowledge in classrooms); differentiation of forms of workingwith students while applyinginnovative methods.

Quite interesting is Polish experience in the matter, namely, the CCISO Certification, that is an industry-leading programme recognizing the real-world experience necessary to succeed at the highest executive levels of information security (Warsaw, Poland).The CCISO programme trains individuals who are looking to make the jump from middle management to the executive ranks by focusing on high-level management skills specifically needed for IS executives. From project to audit management, procurement and finance, to strategy and policy, the students are taught to steer complex security programs strategically and successfully. The CCISO programme was created and is taught by sitting high-level information security executives from across industries, resulting in the most relevant, challenging, and applicable content on the market. It must be noted that the 
Certified CISO course has certified leading information security professionals around the world and is the first of its kind training and certification programme aimed at producing top-level Information Security Leaders. The CCISO does not focus solely on technical knowledge but on the application of information security management principles from an executive management point of view. The CISO aims to bridge the gap between the executive management knowledge that CISOs need and the technical knowledge that many aspiring CISOs have (EC-Council CISO Programme, 2017).

Great Britain belongs to those European countries, where the standards of using information technologies in teaching various subjects are adopted at the legislative level. It must be noted that Great Britain nowadays has the most detailed standards among European countries. First they were launched in 1989 as a component of the structure of professional training.

Thus, Government requirements for the curriculum include the following provisions: when needed and when not needed and how to use information technologies in teaching; how information technologies can be used in groups of students; how information technologies can be used in planning, including the use of information technologies for training and choosing information sources; how to evaluate work using information technologies; how information technologies can be used at the current level (UK Government, 2017).

Information technologies in the education system of Great Britain, in particular in professional training of security specialists, as experience of the Open University has shown, are undeniably decisive. Indeed, due to information technologies established by the Open University there have been created effective inter-institutional knowledge bases for quality assurance providing learning organization and positive experiences dissemination; there have been introduced and improved the latest forms and means of both training and professional growth; there have been established special programmes for distance learning courses and projects, in particular, online or electronic courses for different groups of those individuals who wish to obtain education; there have been conducted fundamental researches in such areas as educational technologies and information technologies; there have been implemented innovative techniques ensuring high quality of educational services, in particular, in professional training of security specialists (Lane, 2012).

\section{CONCLUSIONS}

So, we have studied the use of information technologies in professional training of future security specialists in the United States, Israel, Poland and Great Britain,. The process of expanding learning techniques through information technologies has been emphasized. Four directions of US Education Reform have been outlined. The distinctive features of theory and methodology of using information technologies in the United States have been highlighted. The learning models in Israel have been described. The aim of future specialists' training in Poland has been formulated. The methodological and practical components of future security specialists' training of have been analyzed. It has been indicated that nowadays Great Britain has the most detailed education standards in Europe. It has been pointed out that studying experience of other countries contributes to determining a strategy for using information and communication technology in education. It has been concluded that methodical and practical training of future security specialists for using information technologies should be related to practical skills. It has been found out that motivation play an important role in developing future security specialists' practical skills. It has been proved that pedagogical professionalism promotes achievements of science and technology.

Prospects for further researches are seen in studyingthe peculiarities of professional training of future security specialists in leading European countries. 


\section{REFERENCES}

1. Collis, B. (2013). Information technologies for education and training. In H. H. Adelsberger, B. Collis, J. M. Pawlowski (Eds.), Handbook on information technologies for education and training (pp. 1-20). Berlin: Springer-Verlag.

2. Davis, N. (2003). Technology in teacher education in the USA: whatmakes for sustainablegoodpractice? Technology, pedagogy and education, 12 (1), 59-84.

3. Denning, D. (1998). Information security and welfare. New York, NY: Addison-Wesley.

4. EC-Council CISO Programme. (2017). CCISO Training Warsaw, Poland. Retrieved from https://ciso.eccouncil.org/cciso-certification/training-warsaw-poland/.

5. Educational Technology. (2017). Free and opensourcelearning management systems. Retrieved from https://educationaltechnology.net/free-open-source-learning-management-systems/.

6. Harasim, L. (2006). Assessing online collaborative learning: a theory, methodology and toolset. In B. Khan (Ed.), Flexible learning in an information society (pp. 282-293). Hershey, PA: Idea Group Publishing.

7. Hooper, S., \& Rieber, L. (1995). Teaching with technology. In A. C. Ornstein (Ed.), Teaching: theoryintopractice, (pp. 154-170). Needham Heights, MA: Allyn and Bacon.

8. ISA-Israel. (2017). Academic/Theoretical Distance Cerfitication. Retrieved from https://securityacademy.com/academic-theoretical-distance-certification/.

9. Lane, A. (2012). Widening participation in higher education through open educational resources. In A. Okada, T. Connolly, R. Scott (Eds.), Collaborative Leaning 2.0: open educational resources (pp. 1-15). Hershey, PA: Information Science Reference.

10. Meishar-Tal, H., Yair, Y., \& Tal-Elhasid, E. (2010). Institutional implementation of Wikis in higher education: the case of the Open University of Israel (OUI). In G. Veletsianos (Ed.), Emerging technologies in distance education, (pp. 215-230). Edmonton, AB: AU Press.

11. Security Specialists. (2017). Abousus: technology. Retrieved from http://securityspecialists.pro/technology.html.

12. Sherman, M. (2009). Foreword. In C. R. Payne (Ed.), Information technology and constructivism in higher education: progressive learning frameworks (pp. XVIXVIII). Hershely, PA: Information Science Reference.

13. The Open University of Israel. (2017). The Open University of Israel ranked highest for teachingquality. Retrieved from http://www.openu.ac.il/en/pages/Student Survey.aspx.

14. Tomei, L. (Ed.). (2007). Online and distance learning: concepts, methodologies, tools and applications. Hershey, PA: Information Science Reference.

15. UK Government. (2017). Government Information Technology. Retrieved from https://www.gov.uk/government/collections/ict-strategy-resources.

16. U.S. Department of Education. (2009). Secretary Arne Duncan speaks at the 91st annual meeting of the American Council on Education. Retrieved from https://www2.ed.gov/news/speeches/2009/02/02092009.html.

17. U.S. Department of Education. (2010). Transforming American Education. Learning Powered by Technology. National Education Technology Plan 2010. Retrieved from https://www.ed.gov/sites/default/files/netp2010.pdf. 